\title{
Sample size and the detection of a hump-shaped relationship between biomass and species richness in Mediterranean wetlands
}

\author{
Espinar, J.L. \\ Departamento de Geoecología, Instituto de Recursos Naturales y Agrobiología de Sevilla (CSIC), \\ P.O. Box 1052, ES-41080 Sevilla, Spain; Present address: U.S. Geological Survey, National Wetlands Research Center, \\ 700 Cajundome Blvd., Lafayette,LA 70506,USA; E-mail jespinar@usgs.gov; jlespinar@irnase.csic.es
}

\begin{abstract}
Questions: What is the observed relationship between biomass and species richness across both spatial and temporal scales in communities of submerged annual macrophytes? Does the number of plots sampled affect detection of humpshaped pattern?

Location: Doñana National Park, southwestern Spain.

Methods: A total of 102 plots were sampled during four hydrological cycles. In each hydrological cycle, the plots were distributed randomly along an environmental flooding gradient in three contrasted microhabitats located in the transition zone just below the upper marsh. In each plot $(0.5 \mathrm{~m} \times 0.5 \mathrm{~m})$, plant density and above- and below-ground biomass of submerged vegetation were measured. The hump-shaped model was tested by using a generalized linear model (GLM). A bootstrap procedure was used to test the effect of the number of plots on the ability to detect hump-shaped patterns.

Result: The area exhibited low species density with a range of 1 - 9 species and low values of biomass with a range of 0.2 $87.6 \mathrm{~g}$-DW / $0.25 \mathrm{~m}^{2}$. When data from all years and all microhabitats were combined, the relationships between biomass and species richness showed a hump-shaped pattern. The number of plots was large enough to allow detection of the hump-shaped pattern across microhabitats but it was too small to confirm the hump-shaped pattern within each individual microhabitat.

Conclusion: This study provides evidence of hump-shaped patterns across microhabitats when GLM analysis is used. In communities of submerged annual macrophytes in Mediterranean wetlands, the highest species density occurs in intermediate values of biomass. The bootstrap procedure indicates that the number of plots affects the detection of hump-shaped patterns.
\end{abstract}

Keywords: Bootstrap; Diversity; Doñana; GLM; Mediterranean; Salt marsh; Species richness; Submerged macrophyte; unimodal relationship.

Abbreviations: $\mathrm{AIC}=$ Akaikes information criterion; $\mathrm{GLM}=$ Generalized linear model.

Nomenclature: Valdés et al. 1987; Corillion 1961 and Wood \& Imahori (1965) for charophytes.

\section{Introduction}

In the last two decades, the relationship between species richness (or diversity) and biomass (or productivity) and the possible mechanisms behind the observed pattern have been an important topic in community ecology and constitute one of the most controversial issues related to diversity patterns (Rosenzweig 1995). The originally proposed model for the relationship between biomass and species richness (i.e. maximum species richness occurs at intermediate levels of biomass; see Grime 1973; Al-Mufti et al. 1977) has been the subject of an important discussion. Recently, this relationship has been the subject of several reviews that have organized the information of this topic (Waide et al. 1999; Grace 1999; Mittelbach et al 2001). Spatial scale has been treated in different studies, and the biomass-species richness relationship does seem to be scaledependent. The occurrence of hump-shaped patterns is more frequent across communities than within communities (Waide et al. 1999; Mittelbach et al. 2001); however, the temporal dynamics of the biomass-species richness relationship has rarely been considered. Only Aarsen et al. (2003), Guo (2003) and Bischoff et al. (2005) considered different successional stages, but none of these authors considered the normal community fluctuation (e.g. interannual variation in annual plant community in seasonal habitats) since, according to Guo (2003), successional data (rather than annual fluctuation) usually covers a broad range in the predictor variable (i.e. biomass). Some authors considered that variability in the predictor variable (i.e. range of biomass observed) plays an important role in allowing the detection of the hump-shaped pattern (Guo \& Berry 1998; Grace 1999; Bhattarai et al. 2004). This variability has been argued as one of the reasons for the lack of occurrence of hump-shaped patterns in fine-scale analyses: it may be that analyses within communities or microhabitats do not cover a wide enough range in the predictor variable. Yet to my knowledge, in both spatial and 
temporal studies only Gross et al. (2000) and Mittelbach et al. (2001) considered the number of plots as a possible factor implied in the detection of hump-shaped patterns.

This study focuses on communities of submerged annual macrophytes in Mediterranean salt marshes. The objective of this study is to explore the univariate relationship between biomass and species richness across spatial scales (both within and across three microhabitats located in an environmental gradient) and across temporal scales (in four hydrological cycles). A 'bootstrap' resampling procedure (Efron 1979; Efron \& Tibshirani 1993 ) is used to examine the effect of the number of plots on the probability of obtaining a significant hump when using generalized linear model (GLM) analysis.

\section{Methods}

\section{Study site and sampling}

Sampling was carried out in a temporary Mediterranean wetland in National Park of Doñana salt marsh in southwestern Spain $\left(37^{\circ} 00^{\prime} \mathrm{N}, 6^{\circ} 38^{\prime} \mathrm{W}\right)$. A total of 102 plots were sampled during four hydrological cycles (19 plots in 1995-1996, 28 plots in 1996-1997, 25 plots in 2001-2002, and 33 plots in 2002-2003). Data sampling was carried out between March and June, the seasonal biomass maximum period for submerged annual macrophytes. In each hydrological cycle, the plots were distributed randomly along an environmental flooding gradient in three contrasted microhabitats located in the transition zone just below the upper marsh (shallow water). These microhabitats differed in terms of their dominant perennial community: (1) 'bare soil' without any perennial cover; (2) Scirpus communities dominated by Scirpus maritimus and Scirpus litoralis, and (3) ArthrocnemumJuncus community, dominated by Arthrocnemum macrostachyum and Juncus subulatus. During the first hydrological cycle, some samples were taken from an abandoned commercial salt-evaporation pond located inside the Arthrocnemum-Juncus community. Multivariate analysis showed that the three community types differed both in terms of water characteristics (salinity, flooding period, $\mathrm{HCO}_{3}^{-}$content, nutrient, and ion composition) and in terms of submerged community compositions (Espinar et al. 2002).

In each plot $(0.5 \mathrm{~m} \times 0.5 \mathrm{~m})$, plant density and aboveground and below-ground biomass of annual species (dry biomass heated at $80{ }^{\circ} \mathrm{C}$ for $72 \mathrm{~h}$ ) were measured. The biomass (i.e. harvest at peak of standing crop in annual communities) was used to estimate productivity. Species richness was used as a measure of diversity. The annual community in the study area was mainly composed of submerged macrophytes (Espinar et al. 2002).
Ranunculus peltatus ssp. fucoides, Damasonium alisma, Elatine alsinastrum (not a strict submerged macrophyte), and the free floating species Lemna minor and Azolla filiculoides were included in the biomass collections.

\section{Statistical analysis}

The hump-shaped pattern was tested by using GLM, assuming a Poisson distribution (given the nature of the analysed dependent variable, i.e. counts of the number of species) and a logarithmic link function (Dobson 2002). Biomass (linear and quadratic function) was used as the predictor variable (see Mittelbach et al. 2001 for the same procedure). Linear, quadratic, and firstorder interaction effects were considered as potentially explanatory. Akaike's information criterion (AIC) was used as a guide for selecting the best model. Models were finally selected after being checked for overdispersion, residual patterns, and possible artefacts derived from extreme values.

The bootstrap (Efron 1979; Efron \& Tibshirani 1993) is a resampling method which considers that, in absence of other data, the distribution of observations in a sample is the best indicator of the distribution in the sampling universe, i.e. resampling a sample with replacement must be equivalent to resampling the same sampling universe. In this case, each sample obtained is considered a 'bootstrap sample', and the distribution of an attribute in the sampling universe can be estimated by its distribution of the same attribute from bootstrap samples.

The critical value for a left-tail test is:

$p_{o}=p-1.645 \sqrt{ } p q \times n$

when $p=$ probability of success, $q=1-p$ is probability of failure, and $n=$ sample size (Brase \& Brase 1987). Considering 200 bootstrap sampling simulations, if $p_{\mathrm{o}}=$ $0.95-\sqrt{ } 0.95 \times 0.5 \times 200$, then $200 \times p_{\mathrm{o}}=185$. Running 200 bootstrap sampling simulations on the 102 plots of the data set, 185 or more significant hump-shaped patterns must be obtained to consider the model significant. Therefore, a positive one-tailed test for $\mathrm{H}_{\mathrm{o}}=p \geq 0.95$ ( $\geq 185$ humps) versus $\mathrm{H}_{1}=p<0.95$ ( $0-184$ humps) was performed. With this procedure the number of plots necessary to obtain 185 hump-shaped patterns in 200 bootstrap simulations was obtained. The GLM described above was run stepwise until the minimum number of plots necessary to obtain 185 hump-shaped patterns in 200 bootstrap samples was obtained. The significance level was fixed at 0.05 for the whole study. 


\section{Results}

\section{Species composition}

During the study period, 21 species of submerged annual macrophytes were collected. Characeae (with nine species) was the most predominant taxonomic group in the study area and was present in a great proportion of the sampled plots (Table 1). The last 2 years of the study period coincided with the occurrence and early expansion of the invasive species Azolla filiculoides in the salt marshes of Doñana National Park. The first samples collected of this species in the study area were stored in the University of Sevilla Herbarium (SEV 163003).

In general, the area showed low species richness with values within the range of $1-9$ species per $0.25 \mathrm{~m}^{2}$ (3.34 $\pm 0.15, n=102)$ and low biomass values within the range of $0.2-87.6 \mathrm{~g} / 0.25 \mathrm{~m}^{2}(17.68 \pm 1.71, n=102)$.

Number of plots required to detect the hump-shaped pattern

Only when considering the data of all years and all microhabitats together, the relationship between biomass and species richness show a significant, positive quadratic effect with negative coefficient, thus creating a hump-shaped pattern (Table 2; Fig. 1H). Together, linear and quadratic effects are significant and show the best-fit model sensu AIC. The fit model in this study explains $13 \%$ of total species richness variance. Neither within data from an individual year (all communities per year) nor within data from an individual microhabitat
Table 1. List of species and frequency (\% occurrence in 102 samples; rounded off to whole numbers). Data are for all hydrological cycles (1995-1996, 1996-1997, 2001-2002, and 2002-2003) and all microhabitats (i.e. bare soil, Scirpus communities, and Arthrocnemun-Juncus communities).

\begin{tabular}{lc}
\hline Taxon & Frequency (\%) \\
\hline Pteridophytae & 2 \\
Azolla filiculoides & \\
Hepaticae & \\
Riella helicophylla & 6 \\
Riella notarisii & 1 \\
Characeae & \\
Chara galioides & 66 \\
Chara aspera & 7 \\
Chara connivens & 22 \\
Chara canescens & 38 \\
Chara oedophylla & 2 \\
Nitella hyalina & 22 \\
Tolypella glomerata & 1 \\
Tolypella hispanica & 3 \\
Tolypella salina & 2 \\
Lamprothamnium papulosum & 1 \\
Spermatophytae & \\
Callitriche truncata ssp. occidentalis & 46 \\
Althenia orientalis & 3 \\
Ruppia drepanensis & 35 \\
Zannichellia obtusifolia & 36 \\
Damasonium alisma & 10 \\
Elatine alsinastrum & 2 \\
Ranunculus peltatus ssp. fucoides & 32 \\
Lemna minor & 2 \\
\hline
\end{tabular}

(all year per microhabitat) was there a significant humpshaped pattern between biomass and species richness (Fig. 1A-G).
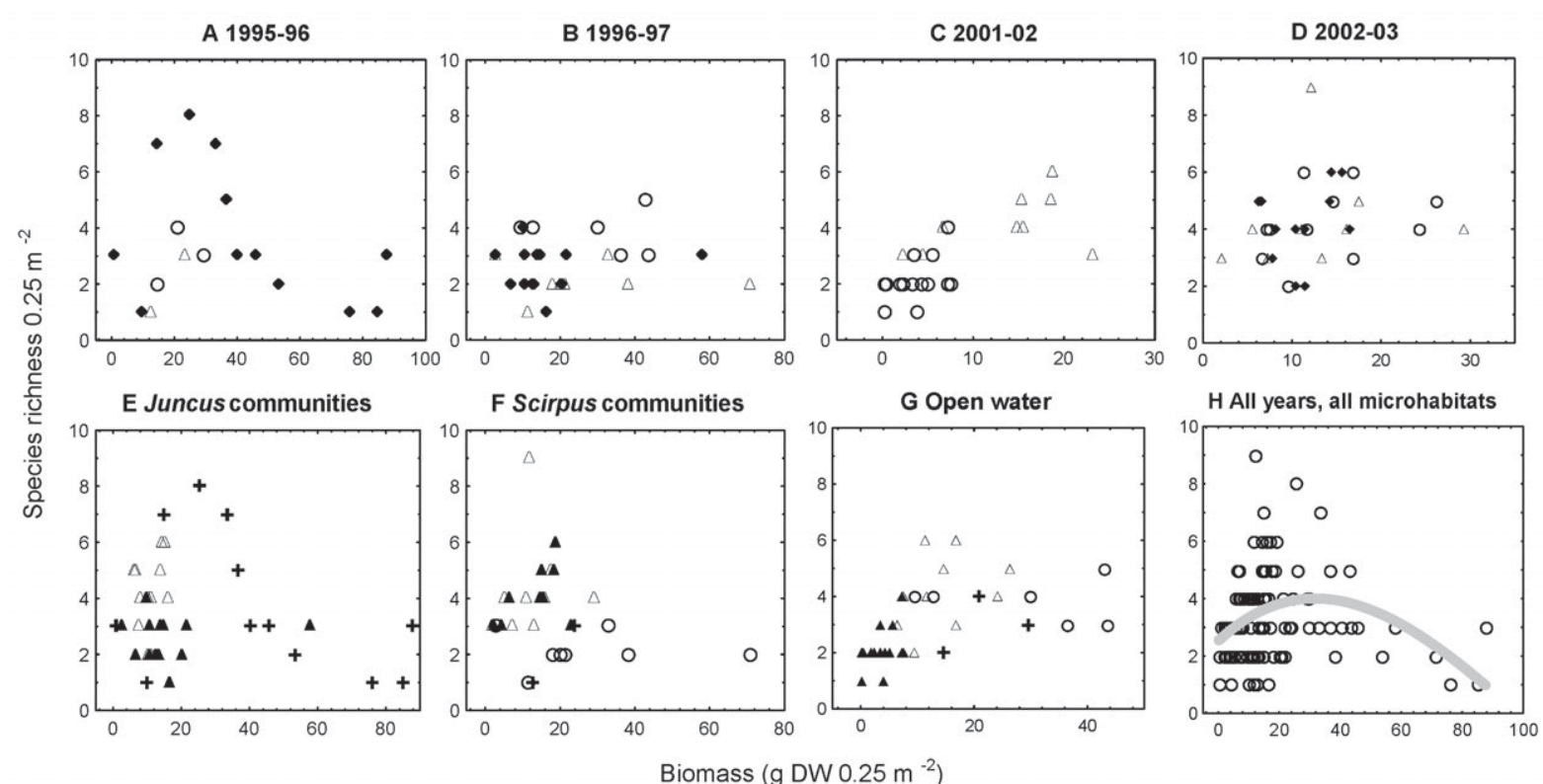

Fig. 1A-H. Species richness versus biomass. A-D. All microhabitats within each study year $(\bullet$, Juncus communities; $\triangle$, Scirpus communities; $\bigcirc=$ open water). E-G. Within each microhabitat and during all study years (+ = cycle 1995-1996; $\boldsymbol{\Delta}=$ cycle 19961997; $\bigcirc=$ cycle 2001-2002; $\triangle$ = cycle 2002-2003). H. All study years across all microhabitat; the grey line indicates the result of the fitted logistic models obtained with GLM (see Table 2). 
The results of the bootstrap procedure indicate that the minimum number of samples for obtaining a significant hump with GLM in the study data set is 78 . If fewer than 78 samples are used, it is not possible with the study data set to obtain a hump-shaped pattern in the relationship between species richness and biomass.

\section{Discussion}

\section{Community composition}

Communities of annual submerged macrophyte constitute a very important functional group in wetlands and are involved in several important processes related to primary production, maintenance of water quality, and control of nutrient cycles in coastal wetlands. The species pool in the study area is formed by 21 species with different phylogenetic origins but is dominated by Characeae. The community contains species of special interest in conservation in seasonal wetlands, such as Riella helycophylla (European Union Habitat Directive 92/43/EEC and Berne Convention). Furthermore, the plant communities are recognized in the European Union Habitat Directive 92/43/EEC.

The community of submerged annual macrophytes in the study area shows similar biomass and species richness ranges as those reported for annual desert communities (Guo \& Berry 1998) and lower biomass and species richness ranges than those reported by Garcia et al. (1993) for terrestrial annual grassland in the same study area.

\section{The hump-shaped patterns}

In the study area, when the relationship between species richness and biomass was measured across all microhabitats and across all years, a significant humpshaped pattern was found. In communities of submerged annual macrophytes in Mediterranean wetlands, the highest species richness occurs at intermediate values of biomass. These results agree with Grime (1973) and Al-
Mufti et al. (1977) and with the results obtained by other authors (see reviews in Waide et al. 1999; Grace 1999; Mittelbach et al. 2001).

Several mechanisms about how productivity affects species richness have been proposed (reviews in Waide et al. 1999; Grace 1999). In the study area, natural disturbance (mainly annual variation of salinity and flooding period) could play a primary role in determining species richness. A significant speciesrichness response to productivity variation could simply be caused by a covariation between intensity of disturbance and productivity. Both disturbance factors, salinity and flooding period, can affect species richness by indirect effect through biomass (salinity and flooding period affect biomass production of submerged macrophytes; Grillas et al. 1993). Salinity and flooding can have direct effects as well by affecting the number of species able to live in the area (species pool), i.e. only a few species are capable of living in highly saline water and few submerged macrophyte species are able to complete their cycles in only a few weeks of flooding.

Biomass variation explains only $13 \%$ of the variance in the species richness data. This value is lower than the average variance explained with bivariate analyses for herbaceous communities (25\% sensu Grace 1999). Obviously other important factors are affecting species richness in the study area. A multivariate approach including other important environmental factors and perennial cover (Espinar et al. 2002) is required to better explain variance in species richness.

\section{The number of plots affects detection of hump-shaped patterns}

The result of bootstrap resampling indicates that, in order to identify a significant hump-shaped pattern in the study data set, it is necessary to have at least 78 plots, and there is a high probability that the hump-shaped pattern will not be perceptible (within each year or within each microhabitat) if the number of samples is lower than 78 .

Table 2. Results of generalized linear model (GLM) analysis of the species density in 102 plots in the salt marshes of Doñana National Park. Data have been modelled by using GLM, with an assumed Poisson distribution of the dependent variable (species richness, number of species / $0.25 \mathrm{~m}^{2}$ ), $\log$ link function, and both linear and quadratic effects of the predictor variable (biomass; B, $\left.\mathrm{B}^{2}, \mathrm{~g}-\mathrm{DW} \times 0.25 \mathrm{~m}^{-2}\right)$.

\begin{tabular}{cccccccccc}
\hline & \multicolumn{3}{c}{ Whole model } & & \multicolumn{3}{c}{ Biomass (B) } \\
& \multirow{2}{*}{ AIC } & $R^{2}$ & $P$ & Effect & Coefficient & SE & Wald's $\chi^{2}$ & $P$ \\
\hline All plots & \multirow{2}{*}{373.26} & \multirow{2}{*}{0.13} & \multirow{2}{*}{0.0069} & B & 0.027 & 0.0098 & 7.773 & 0.0054 \\
& & & & & $\mathrm{~B}^{2}$ & -0.00042 & 0.00014 & 8.494 & 0.0035 \\
\hline
\end{tabular}


The range of the predictor variable (biomass) is an important factor in the detection of a hump-shaped pattern (Guo \& Berry 1998; Grace 1999; Bhattarai et al. 2004). In the case of this study, when using the complete data set as a guideline for which biomass ranges should be expected to include a real hump-shaped pattern, it is possible to detect the hump-shaped pattern within a biomass range of 1 - $85 \mathrm{~g}$-DW / $0.25 \mathrm{~m}^{2}$ (Fig. 1H). This range is present across all communities and hydrological cycles except for the 2001-2002 and 2002-2003 hydrological cycles and for open water (Fig. 1C, D, G). The range of biomass could be considered as an alternative hypothesis for explaining the lack of detection of hump-shaped patterns at the fine scale. The 'suitable' biomass range was present in the 1995-1996 and 19961997 hydrological cycles as well as one in Juncus communities and Scirpus communities; however, it was not possible to detect a hump-shaped pattern in these cases.

The quadratic function fit to Fig. $1 \mathrm{H}$ does not show a perfect fit to original data. Judging from the point scatter in Fig. 1H, the real position of maximum diversity is located to the left of the fitted curve using a quadratic function. Cornwell \& Grubb (2003), comparing the result of GLM and least squares regression, concluded that the choice of model changed the location of the species-richness peak by $1.6 \%$ to $3.6 \%$. In addition, the long right tail of the point scatter is not properly picked up by the fitted curve. However for this study it is not the shape of the curve that matters but the occurrence of a non-linear (hump-shaped) response. I have used a simple approach to fitting the diversity response to biomass. This method has been recently used by several scientists to evaluate the relationship between biomass and species richness (Mittelbach et al. 1999; Bhattarai et al. 2004). It may be that alternative and more flexible approaches to fitting the response (piecewise or higher order polynomials or a cubic spline smoothers) could reveal a better fit. An enhanced fit could however cost additional degrees of freedom and lack of generality.

Moore \& Keddy (1989) explored relationships within and across community types in wetlands and suggested that the Grime model is not effective at the fine scale. Guo \& Berry (1998) employed a similar sampling approach and did not find the hump-shaped pattern within each individual microhabitat, but they did find it across all of the microhabitats. Furthermore, Guo \& Berry (1998) found that one phase of the unimodal curve was present in each microhabitat and that it represented the species richness-biomass relationship in terms of a portion of an environmental gradient. In the context of habitat heterogeneity and environmental gradient, it was not possible with the present data to test whether, as Guo \& Berry (1998) suggested, one phase of the unimodal curve was present in each microhabitat, thus representing the relationship between species richness and biomass in terms of a portion of the environmental gradient (i.e. pattern accumulation hypothesis).

This study suggests that there is not enough evidence to assume that the hump-shaped pattern does not occur at fine scales (within each microhabitat sensu Guo \& Berry 1998, or between vegetation types sensu Moore \& Keddy 1989). Neither Moore \& Keddy (1989) nor Guo \& Berry (1998) were able to detect hump-shaped patterns within communities, but this may be because the authors employed as the subject of across-spatialscale analysis a summary of the plots obtained within spatial scales, i.e. the number of plots employed for across-community analysis was higher than the number of plots employed for within-community analysis. Grytnes (2000) was able to detect hump-shaped patterns within communities by using an equal number of samples in analysis within and across each community.

With an accurate procedure to identify a unimodal relationship in accordance with the distribution of the original data (Mittelbach et al. 2001), this study concludes that other approaches to the same problem must consider the results of the bootstrap procedure (i.e. it is necessary to have a minimum number of plots to obtain a hump-shaped pattern in any data set) in order to interpret the difference in species richness-biomass relationship patterns observed within microhabitat (Guo \& Berry 1998) or within vegetation types (Moore \& Keddy 1989). Perhaps the difficulty in finding the humpshaped patterns within communities or within microhabitats is caused by the methodology employed rather than by an absence of the process at fine scales.

\begin{abstract}
Acknowledgements. Thanks to L. Clemente and U.S. Geological Survey National Wetlands Research Center for the facilities used while preparing the manuscript. Thanks are due to $\mathrm{D}$. Johnson for the bootstrap resampling procedure, and to $\mathrm{J}$. Grace for comments on the manuscript. Financial support was provided by the Spanish Ministry of the Environment (MMA, project 05/99) and the Junta de Andalucía (research group \#4086). I am also grateful for the constructive comments by three anonymous reviewers and especially by the co-ordinating editor R. Ejrnæs.
\end{abstract}

\section{References}

Aarsen, L.W., Laird, R.A. \& Pither, J. 2003. Is the productivity of vegetation plots higher or lower when there are more species? Variable predictions from interaction of the 'sampling effect' and 'competitive dominance effect' on the habitat templet. Oikos 102: 427-433. 
Al-Mufti, M.M., Sides, C.L., Furness, S.B., Grime, J.P. \& Band, S.R. 1977. A quantitative analysis of shoot phenology and dominance in herbaceous vegetation. J. Ecol. 65: 759-791.

Bhattarai, K.R., Vetaas, O.R. \& Grytness, J.A. 2004 . Relationship between plant species richness and biomass in an arid sub-Alpine grassland of the Central Himalayas, Nepal. Folia Geobot. 39: 57-71.

Brase, C.H. \& Brase, C.P. 1987. Understandable statistics. Concepts and methods. D.C. Heath and Company, Lexington, MA, US.

Bischoff, A., Auge, H. \& Mahn, E.G. 2005. Seasonal changes in the relationship between plant species richness and community biomass in early succession. Basic Appl. Ecol. 6: 385-394.

Corillion, R. 1961. Les végétation précoces de Charophycées d'Espagne Méridionale et du Maroc Occidentale. Rev. Gén. Bot. 804: 317-331.

Cornwell, W.K. \& Grubb, P.J. 2003. Regional and local patterns in plant species richness with respect to the resource availability. Oikos 100: 417-428.

Dobson, A.J. 2002. An introduction to generalized linear models. 2nd. ed. Chapman \& Hall, London, UK.

Efron, B. 1979. Bootstrap methods: another look at the jackknife. Ann. Stat. 7: 1-25.

Efron, B. \& Tibshirani, R. 1993. An introduction to the bootstrap. Chapman and Hall, London, UK.

Espinar, J.L., García, L.V., García Murillo, P. \& Toja, J. 2002. Submerged macrophyte zonation in a Mediterranean salt marsh: a facilitation effect from established helophytes? $J$. Veg. Sci. 13: 831-840.

García, L.V., Marañón, T., Moreno, A. \& Clemente, L. 1993. Above-ground biomass and species richness in a Mediterranean salt marsh. J. Veg. Sci. 4: 417-424.

Grace, J.B. 1999. The factors controlling species density in herbaceous plant communities: an assessment. Perspect. Plant Ecol. Evol. Syst. 2: 1-28.

Grime, J.P. 1973. Competitive exclusion in herbaceous vegetation. Nature 234: 344-347.

Gross, K.L., Willig, M.R., Gough, L., Inouye, R. \& Cox, S.B . 2000. Patterns of species density and productivity at different spatial scales in herbaceous communities. Oikos 89: 417-427.

Grytnes, J.A. 2000. Fine-scale plant species richness in different alpine vegetation types: relationship with biomass and cover. J. Veg. Sci. 11: 87-92.

Guo, Q. 2003. Temporal species richness-biomass relationships along successional gradients. J. Veg. Sci. 14: 121128.

Guo, Q. \& Berry, W.L. 1998. Species richness and biomass: dissection of the hump-shaped relationships. Ecology 79: 2555-2559.

Moore, D.R.J. \& Keddy, P.A. 1989. The relationship between richness and standing crop in wetlands: the importance of scale. Vegetatio 79: 99-106.

Mittelbach, G.G., Steiner, C.F., Schneider, S.M., Gross, K. L., Reynolds, H.L., Waide, R.B., Willing, M.R., Dodson, S. I. \& Gough, L. 2001. What is the observed relationship between species richness and productivity? Ecology 82: 2381-2396.

Rosenzweig, M.L. 1995. Species diversity in space and time. Cambridge University Press, Cambridge, UK.

Valdés, B., Talavera, S. \& Fernández Galiano, E. 1987. Flora vascular de Andalucía Occidental. Ketres, Barcelona, ES.

Waide, R.B., Willig, M.R., Steiner, C.F., Mittelbach, G.G., Gough, L., Dobson, S.I., Jaday, G.P. \& Parmenter, R. 1999. The relationship between productivity and species richness. Annu. Rev. Ecol. Syst. 30: 257-300.

Wood, R.D. \& Imahori, K. 1964. A review of the Characeae. J. Cramer, Weinheim, New York, NY, US.

Received 19 September 2005;

Accepted 13 December 2005. Co-ordinating Editor: R. Ejrnæs. 